\title{
Standards of performance and aesthetics in counselling and beyond
}

\section{Morten Nissen}

\author{
Submitted to British Journal of Guidance \& Counselling
}

\begin{abstract}
The article discusses performance standards in relation to Danish experiments with expanding drug counselling into 'aesthetic documentation' which is a hybrid of art with narrative practice. This relation is problematic, since the instrumental use defies the point in art, and since 'aesthetic documentation' is the attempt to move beyond the standards of counselling. On the basis of brief outlines of the concepts of performance and standards, a critique is sketched of the strategy of 'customizing' counselling through formalized feed-back as a way of addressing the troublesome issue of client subjectivity. Then five claims are made about 'aesthetic documentation' as an alternative: The art works can be seen as prototypes rather than rigid standardizations; they represent collaboration rather than individualized performance; they work as staging or display in close connection with the substantial meaning of activities and their products; they objectify and thus achieve social recognition of clients and professionals; as art, they open to flexible, diverse and transforming attributions of meaning and value; and they address social problems rather than individualized malfunctions. In conclusion, this is seen as a way of overcoming the stigmatizing implications in counselling, as well as model for a trans-disciplinary form of knowledge and reflection that is different from the dominant scientific and religious forms.
\end{abstract}

\section{Introduction}

In November, 2013, I attended a conference on The Subject of Addiction in Nottingham, UK, together with two counsellors and an artist who worked at municipal services for young people with drug problems in Copenhagen and Elsinore, called U-turn and Helsingung, respectively. We presented our collaboration partly in the form of a gallery that displayed art work - images, poems, song, videos etc. - made as a way of performing and expanding drug counselling. Our hope was that this collaboration of counsellors, artists, clients and researchers could be modeled as a prototype at several levels. First, and most importantly, the art work was itself a kind of portraits and self-portraits that would represent personal narratives of value and worth, struggle and hope, for a public; as such, they provided models for youth life, as strong alternatives and corrections to the often derogatory and stigmatizing ways the young clients had otherwise been depicted. Building on and expanding the methodologies of narrative practice that were important inspirations (White 2007), the counselors called it 'aesthetic documentation'. Second, the gallery - along with internet sites and articles in counselling and social theory journals (Nissen 2012, Halberg 2013, Nielsen and Kofod 2013, Nissen 2014, Bank and Nissen 2016) - provided vivid illustrations of this way of doing counselling and of working with young drug users ${ }^{1}$. Third, this

\footnotetext{
${ }^{1}$ See helsingung.nu, uturn.kk.dk and https://vimeo.com/user15607750 - plus (xx - website to be launched August,
} 
was one expression of a 'relational aesthetics' that pushed the limits of art to include dialogues on its social relevance and implications (Bourriaud, 2005). Fourth, and finally, the whole infrastructure of activities, artifacts and standards would make out a form of knowledge and competence that could serve as a much needed alternative, not only to traditional academic and professional disciplines, but also to their dominant current successors: Evidence-based practices. In particular, it would represent a way of engaging expert professionals in dialogue with users, which did not predefine their service as a commodity, whether pre-packed and labelled, or customized.

This text is an edited version of my own contribution to our presentation at the conference. At the time, I was leading a research project on standards and subjects, of which one part was about 'user-driven standards in social work' (Nissen, 2016) ${ }^{2}$. The project connected research on standards and standardization with the rising recognition and power of the user in public services, in particular in drug treatment and counselling. This was the angle from which I approached matters and took part in the collaboration ${ }^{3}$. For this reason, this article will mostly focus on the fourth aspect: Articulating the concepts of performance, standards, and aesthetics implied in the practices and models displayed.

It is probably useful right off to stress that my academic role, then at the conference and now as author, is not to sanction validity or conceptual clarity, nor is it to provide frameworks or foundations. Mine is a specialized practice in dialogue with those of the counsellors - it is not above them or underlying them. It is better to think of the articulations that I propose as a repertoire, even if part of what they are for is to reshape commitments and rethink relevances (on the epistemology implied, see e.g. Stengers 1997, Jensen 1999, Nissen 2009, Nissen 2013).

\section{Performance and standards}

One of the interests we have in common is performance. It is a key term in the social sciences traditions that we share as inspiration, to the point that some even refer to a "performative turn" (Turner 1995, Butler 1997, Martin 2007). To state this approach very simply, the things we are are mostly things we do. We can often change by doing otherwise. Sometimes, of course, that is not easy - many kinds of resources and premises must be in place for a performance to succeed. But part of why it isn't easy is that we can't imagine other performances; and so we don't set out looking for ways to provide the right conditions for them. An important way to encourage performative imagination is to show it. Performing is doing, but it is also showing, displaying; repeating acts, and through that, directing attention to them, facilitating reflection and possible change. This may be done in the flow of activities, for instance as humour, but it can also be specialized 'performance' activities. Further, it is much amplified by modelling - by creating artifacts that serve to make acts present again - thus, to re-present them ${ }^{4}$.

\footnotetext{
2016). Please read those texts or visit those websites for further information about 'aesthetic documentation'

${ }^{2}$ Note that 'social work' in a Danish context is different from its UK version. For one thing, it is a generic term for a range of professions, including - as is mostly the case here - academically trained psychologist. See, to this Nissen, 2012

${ }^{3}$ Although, it should be noted, this specific project was only one phase of a much longer history of collaboration, which stretches back to the 1980s.

${ }^{4}$ We use the Danish translation 'fremstilling', which means enacting, rendering, and displaying, but even also creating. Those with an interest in Heidegger's approach to technology will perhaps note an etymological connection with his concept 'Gestell' and its derivatives; in fact, "fremstilling" is at once Darstellen (rendering) and
} 
In their work with young drug users, the counsellors are interested in creatively modelling ways to change performances, ways to perform inspiring and convincing narratives about how life could $b e^{5}$. This has a long history. Performance has been important in the traditions of social work and youth work in these Copenhagen communities for decades. Thus, street happenings and shows were a key ingredient of the grassroots youth work community "The Crew" which I studied in the early 1990s (Nissen 2012). This is of course only one out of many examples of the pedagogical or therapeutic use of performance. Variously drawing on traditions and theories of theatrical performance (Brecht 1982, Jameson 1998, Boal 2000, Høgsbro 2014) - much more than on the psycho-drama or gestalt therapies that would appear to be the 'classics' within counselling - this has been taken up recently, for instance, in New York (Newman and Holzman 1996), London (Sloan 2014), and Sao Paulo (Liberali, 2000).

But performance is a word that means many things. It is also a key term in standardization: Performance standards. Here, the meaning is much narrower: To perform means here only to enact, to do something which is stipulated in advance - for instance, to run a $100 \mathrm{~m}$ dash in no more than 10 seconds. The quality (what it is) is fixed, and so the focus is on the only variable, which is some quantity (how fast, how much etc.). This matches the idea of standardization: of standards described and prescribed, using models of practices to regulate them. And it matches the idea that performing reproduces certain cultural patterns that already exist.

Figure 1 is a cartoon version of Judith Butler's theory that gender is performed and only thereby reproduced (Butler 1993). The boy always gets to be the boy... Yet we can already see that maybe the girl has had enough of it. What would happen she got to be the boy? This may sound weird, or even queer, but it is a bit like: What if a young drug user got to be an artist? Butler, too, is preoccupied with performance as enactment of given subjectivities; but her point is that it could be otherwise. Once we see that gender, or addiction, or singer-songwriting, is something that is performed, we can see other possibilities. And that opens to a different approach to performance: not as the enactment of a pregiven pattern, but as creative acts.

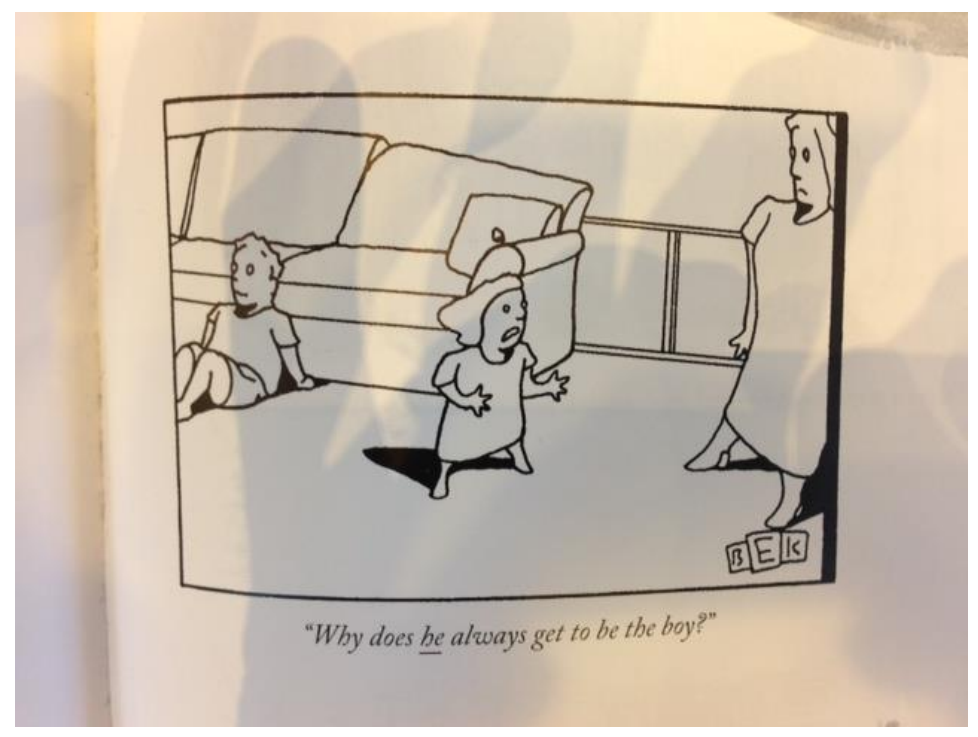

Figure 1

In fact, this is not only the case when something new and unheard of is performed. Even reenacting something is already a remaking of it, opening it to debate and possible change. This is one way to understand the magic of theater and art in general. And standards, too: Standards are modeled to stipulate and regulate, but they still have to be performed in each instance, and that is itself a creative act that opens to possibilities of transformation, of setting new standards (Bowker and Star 1999, Timmermans and Epstein 2010, Nissen 2016).

Herstellen (production), and thus the practical root of Vorstellen (imagination).

5 One 'aesthetic documentation' project was called 'Could Life Be...'. This is discussed in Nissen (2014). 


\section{Standards of counselling}

In counselling, we can see similar approaches. A lot of people are busy defining performance standards for counselling that works (e.g. Rowland \& Goss, 2013). Evidence-based counselling is counselling that is performed in a way that meets certain performance standards - which is then said to lead to certain desired results. But they run into a problem, since it takes at least two to do counselling. There is no direct and immediate causality from the counsellor's performance to the more or less curative effects on the client. At the end of the day, the client is the one who has to cash in any gains achieved in counseling. The counsellor may do all the right things and still the client neglects to change. The subjectivity of the client is inescapable.

This has been known and discussed all through the 20th century in different vocabularies since Freud. The history of psychotherapy is in many respects a history of the ways in which client subjectivity has been objectified, colonized, fenced off, and otherwise handled, once given over to the therapist. But in recent decades, an important cultural-historical transformation has occurred. People are no longer expected to surrender to the authority of the therapist, not even if they are diagnosed with diseases, and not even if those diseases are psychological or psychiatric; not even addicts. Users have been mobilized in governance, under various catchwords, in the general framework of New Public Management.

Although the mobilization of user experience, user assessment etc. appears the opposite, it really works in tandem with the trend toward governance through standards. This is because a meta language is needed. User experience was no great epistemological problem in the 20th century because experts were trusted with the authority to interpret and translate it. But now that users are pitted against experts, trust is replaced with standardization and numbers (cf. Porter 1995, Thorgaard, 2010). The subjectivity of the client is still pivotal, but in a new way: not as objectified in the expert's language (as denial, anxiety, automatic thoughts, resistance etc.), but in a logic of choice (Mol 2008), as the user or customer who choses, evaluates and decides about the service provided.

In a word, counselling is being based on evidence that is made and treated as valid in the encounter with clients (and other stakeholders). For this reason, performance standards tend increasingly to prioritize collaboration, measure effect as self-reported, and often settle pragmatically for client retention (Norcross 2011). But to do this, you must apply a very conservative, common sense version of what counts as counselling. This is because the logic of choice requires a well-defined standard intervention or service. If you are to measure effects, in a way that is accountable to users and managers, you have to define the service in a way that bases directly on common sense. The boy must always get to be the boy. This leads to the paradox that these quite radical changes in practices and their governance and epistemologies are effected with surprisingly traditional concepts - which may be one reason that these developments are often hard to decipher, for clients, practitioners and researchers alike.

This is a large part of why Cognitive-Behavioral Therapy (CBT) is becoming the standard form of counseling. It is immediately recognizable as a service directed at solving predefined problems or diseases understood in a common sense framework. It matches well with the ICD and DSM, the international diagnostic manuals, in which the disputes over ontologies and metaphysics have long been declared passé - and diagnoses are instead supposedly based purely on empirical data and description. CBT also stages a kind of collaboration. It was originally associated with the classic Modernist ambition to a unified scientific body of knowledge, but it 
has moved toward a more pragmatic epistemology, and is often mixed with some version of client-centered counseling, as in the most widespread drug counseling method, Motivational Interviewing (Miller and Rollnick 1991).

Clients can indeed be met on the basis of descriptive diagnosis. Many users, clients and patients - not to mention relatives - declare diagnosis a relief; and no doubt, it is less stigmatizing than it used to be. Yet, given that psychiatric diagnoses - even those with a massive prevalence, such as depression, ADHD, or dependence - still imply some measure of self-deceit, and thus some weight attributed to expert judgment, there remains a tension between diagnosis and user experience ${ }^{6}$. Even if CBT is collaborative, it still rests on the authority of the expert counsellor. This is perhaps most clearly expressed in the practice of "psycho-education", which assumes and performs an almost caricatured traditional idea of teaching as the channeling of authoritative information about a given disease and the workings of the brain. The authorized knowledge remains unchallenged and only has to be chopped up and fed to the individual client.

This process of chopping up standards for the individual client was always, in principle, required in evidence-based counselling, and treatment more generally (Sackett, Strauss et al. 2000). Typically, this aspect has been acknowledged but given very limited attention. However, this may be changing, since it matches a version of user-driven standards that is becoming widespread in many other spheres of our lives: Customization (cf. Busch 2011). We might compare such customized counselling with a smart-phone: It is made to be customized to each individual user's specific habits and preferences. But it is also a framework that is the same all over the world, and over which the smartphone company rules with absolute authority, once you've chosen the product (at least readers who have Apple products will know what I mean). If such customization is taken to its full implications, does this not challenge the authority of the counsellor? That question is raised by the idea of Feedback-Informed Treatment (FIT; cf. Miller, Duncan et al. 2003). FIT is the ultimate in customized counselling. A continuous and systematic formal feedback from the client - in the form of simple scales on how she thinks she is doing and what she thinks of the sessions - is used to modify the counselling. This, way, the counselling is no longer adapted to meet a generalized performance standard, but rather to what works for the individual client - as measured by herself (which appears to correlate with client retention, cf. Miller, Duncan et al. 2006). This is called 'practice-based evidence'. It is no coincidence that FIT has branched off the Solution-Focused Brief Therapy (SFBT) which boasts a complete rejection of psychological explanation and claims to always take what the client says at face value (De Shazer, 1991). Here we find one current example that numbers are used pragmatically when expert interpretation is given up or denounced. Both SFBT and FIT have attracted the attention of the counsellors I work with, for their radical deconstruction of psychological expertise and for recognizing the voice of the user, drawing on Wittgenstein and Derrida. For this reason, we have discussed it intensely and critically (Nissen and Barington 2016).

Ideally, the user gets exactly what she wants. The customer is always right. This is in fact a wellknown standard in commercial relations. Except for one thing - what does she in fact buy - a conversation with a salesperson? A reflection of her preferred self-image?

That makes me think of the master in Hegel's "dialectics of recognition", or "Master and Bondsman" allegory (Hegel 1977): The Master wins the battle and forces the Bondsman to serve him, to follow his every last whim. But this is how the Master loses in the long run, for through

\footnotetext{
${ }^{6}$ This tension is wonderfully analyzed in Emily Martin's Bipolar Expeditions (2009).
} 
his work, the Bondsman learns and grows, eventually to surpass the Master, who is reduced to a child screaming for fulfilment of his immature needs. A horror image of servitude exaggerated and reverted, known also from the sci-fi films such as The Matrix. When recognition is reduced to immediate preferences, it is emptied and turned around.

Neither SFBT nor FIT challenges the form of treatment and its concomitant stigmatization and power differentials. Metaphorically, the hardware of therapy has not really been touched by the customization of its software and all its apps. Even the most radical deconstruction of the language games of diagnosis and healing, within the therapeutic space, only leads back to the common sense that defines what the customer has come to buy in the first place. It is still a performance standard in that sense, a regulating model that remains within the given, even if the details are left to each client to choose. The counsellor is trained as the actor, performing the version of counsellor that best matches the client's imagination. But the basic act remains the same.

In fact, even the customization itself is standardized. It is really only that a unique (or quasiunique) combination of equally predefined standards has emerged, within the framework, just as all the apps and settings on the smartphone are defined in advance and all that is left to the customer is to combine them. Customization looks like it's something different than standardization, but in fact it's a continuation of the proliferation of formalized standards that is going on.

All this is relevant, as mentioned, because FIT suggests itself in the same communities of practitioners that I discuss here. And I want to oppose it to an alternative articulation of their practices of 'aesthetic documentation' (drawing on, among others, an alternative reading of Wittgenstein and Derrida), as an expanded prototype for how performance standards can be userdriven.

\section{Five claims}

I am going to make five claims about the gallery that I and my collaborators presented, and about the 'aesthetic documentation' practices that produced it - to make the case that they represent a much more radical way to develop and problematize performance standards in counselling. As you will see, I suggest that they should be articulated in terms of a deeper and wider way of addressing the classic qualities of scientific knowledge: Generalization, abstraction, and objectivity - since this is more fruitful than attempting to disregard those qualities.

Again, these claims are not authoritative. They remain debatable. For one thing, I may have misunderstood things and should be corrected in the ongoing dialogue. For another, the data I base on are shaped by my positions and relations in the field, and so they should be expanded, compared to other views and angles. And last but not least, what I suggest depends on what I consider relevant, given not only my standpoint (ethically, politically etc.) but also my specific, sometimes nerdy, pursuits - and my readers should reflect on whether they think it is relevant, too, and for what. In fact, science should always first of all be questioned for its relevance, since it is quite rare that we scientists or researchers actually produce claims that are simply false - or simply true. 


\section{Prototypes}

My first claim is that the performance standards provided here are prototypes. Prototypes are artifacts that hold some generalizing promises or hopes, but in visibly contingent and even sometimes precarious ways, and without hiding their singularity and the situations of their emergence and use. As the word suggests, they are not yet and not quite types (Jensen 1987, Suchman, Trigg et al. 2002, Nissen 2009)). Anyone who listens to the song that Halberg the counsellor produced along with Louie the client and posted on the internet ${ }^{7}$, will realize that this models a unique event with unique persons in unique situations. Or take a look at the "Give a Story" art videos posted by U-turn in Copenhagen, such as the one where Sebastian (client) sings karaoke with his headphones in the middle of a noisy street festival ${ }^{8}$.

That uniqueness doesn't mean we can't learn from all this; far from it, the whole point about it is that it speaks to us, it generalizes. And to be sure, we can only learn from it and bring it home by focusing on some things and forgetting others - to generalize is to perform abstraction. But with prototypes is clear that we leave other things behind when we do take something with us. It is clear that we take different things from it, and it is clear that when we do, we transform it on the way. We know that if we want to learn more, we have to engage with the specifics of Copenhagen or Elsinore municipality, as well as with certain elements of youth subcultures etc. And we know it's not going to be quite the same in Glasgow or Sydney. Perhaps we must change the model slightly, or we need to build an infrastructure around it for it to work. That's basically how people have always learnt from great educational or social experiments, such as those of Paulo Freire in Brazil, Anton Makarenko in Ukraine, or A.S. Neill in England. But it is very different from the medical format that reigns in counseling, which seems to imply a much more rigid and simplistic standardization.

The concept of prototype points to the historicity of standards - which, incidentally, could draw on a reading of (Wittgenstein 2010) that emphasizes how language games are historically situated life forms, rather than discrete patterns that can be manipulated for more or less concealed therapeutic purposes. It also highlights how values and hopes are part of the story, and how standards always, as embedded in historical circumstance, guide evolving dramas. If we take up that emphasis, we can call them prototypical narratives (Nissen 2015). This way of thinking speaks to the fertile tradition of narrative anthropology (Mattingly 2010) as much as that of narrative therapy from which the counsellors have taken inspiration.

\section{Collaboration}

My second claim is that these are prototypes of collaboration. They do not separate what the professional does from what the client does, as it is the case with typical performance standards in counselling, including the ever so feedback-informed treatment. They highlight this aspect in that they are hybrid activities that lead to tangible products; but it is a general characteristic of counselling. The client is not just a user, but also and probably first of all a participant. This is crucial because that is how people really learn, and because the whole approach to activities like counselling or teaching should start from the assumption that they are first of all collective. This was a main point in my book The Subjectivity of Participation (Nissen 2012). The most fertile question the participant asks is not "what's in this for me?", or "am I doing the right thing?", but

\footnotetext{
${ }^{7}$ By March, 2016: https://youtu.be/mD3RVCcNZ9Y

${ }^{8}$ March, 2016: https://vimeo.com/98728123
} 
"who are we, what are we doing, what comes of it, and how does that make sense?" Even when a crucial point is that such collectives are made up of very different people with diverse power and premises - and very different positions, contributions, and gains.

Jean Lave, the anthropologist, once said that "social practice is a dance" (personal communication; but you can read about her theories in Lave and Wenger 1991, Lave 2011). I take that to mean that we continuously create it together, sometimes loving, at other times fighting, but always together. Of course, this is easy to state in general, but hard to practice and govern counselling by, even as both professional accountability and user self-care are cherished. The ways that responsibility is currently split up and shifted around between providers and users of public services do not encourage a reflexive collective approach that allows users to grow as participants. I the final analysis, this requires a development of the 'gift economy' that was emerging precariously in the era of the welfare states (Hart 2006).

\section{Staging}

But the dance could also be a metaphor for the reflexivity or self-consciousness of social life that led Shakespeare to have a character in "As You Like It" suggest that "all the world's a stage", and many social theorists - such as (Goffman 1986) - to agree several hundred years later. This is my third claim. The activities of counsellors and clients are always also staged performances of how it is possible to act; how life could be. We display standards as we act together. Performing is acting, and acting is showing. One person's bow sets the standard for the next person's bend. That is an important part of how we learn when we learn by doing, by participating.

Setting standards is more than just showing how by going through the movements. It is also confirming values. The meaning of who we are and what we are doing is immanent to our practices, as when for instance it makes sense quite directly and immediately to record a song for people to hear. But it is also constantly being displayed, as we modify and adjust our actions to address that meaning. Those two aspects should not be thought of as two separate things. The meaningfulness of songwriting and of being someone who can write and perform songs is at once enacted, displayed, and confirmed. The different 'laminations' of performance (Goffman 1986) - layers of reference and meta-reference - are dynamically interwoven and mutually defined in our activities; this is what endows reflection with meaningful substance and vice versa.

This is very important because performance standards so easily become parodic (Stenner 2016). That is to say, they are detached from the point of the whole thing, and become ends in themselves. Signs that were supposed to refer to meaning, but which take over the whole show as hyper-real signs that are more important than what they refer to (Hanson 1993, Baudrillard, 1994). That is in fact the story of much governance by standards and accountability today. We easily end up saying "who knows how it made sense, but at least I did all the right things".

\section{4a. Objectification}

Yet, this danger of alienation should not lead us to reject the modelling of standards altogether. In fact, my fourth claim is that a key to how aesthetic documentation works is that it externalizes and objectifies what is meaningful. This is basically what creativity means, and it has two dimensions. 
The first is the simple fact that these are artifacts made by us - the clients, the counselors, and the researchers - for a public. When sense and meaning and performance are turned into artifacts, they are objectified: made into objects. They become something solid over time, and something for other people to witness. And thus something to which power and recognition can be attached, through which they get to be mediated.

This was already in a sense the case with gestures and winks of the eye on the dance-floor or in group therapy - especially if those movements are rehearsed and become habits - but it is more visible and gets to be more important when it is built into things. At this level it makes a huge difference whether the things that are made by users and counsellors in places like Helsingung or U-turn are case files with words about "anamnesis", "diagnosis", "social action plan", etc., circulated among professionals, or rather, music and works of art for a general public. Not only in the direct sense of the recognition attributed to the participants - that e.g. Sebastian is seen as someone who took part in making an interesting art video - but also in more roundabout ways, for instance through the ways it mediates connections and relations between different communities, and the ways it invites a public into the discussions about what goes on at Helsingung or U-turn.

The case file and the recorded video are two very different ways to learn about Sebastian, for himself, for us, and then again for him because he knows how he presents himself to us. As already mentioned, just as we could claim that the videos are prototypes of counselling or youth work, we can also see them as prototypes of self-hood. He recognizes himself in that prototypical narrative, not least because of the horizon of hope that is built into it (Mattingly 2010). This is who he is, then: He can use it to remind himself that he is, among other things, a budding video artist, and also a participant in the making of a new kind of youth work that people study even in Nottingham because they are looking for ways to work with the subject of addiction.

\section{4b. Creativity}

And each time, he sees the same images and hears the same song, but he sees and hears something different each time. Because the reservoir of meaning in artifacts like that is endless, and Sebastian is constantly developing and finding himself in new situations. This leads to the second aspect of my claim about creativity. Even though meaning is frozen into things, producing artifacts is always in some sense innovative. This idea goes back to Hegel's notion of the 'cunning of reason' (Hegel 1969) - means are made for ends, but they always tend to go beyond them and even prompt us to rethink our aims, purposes, and values ${ }^{9}$. We also learn this from Jacques Derrida, who shows us how texts can't help being and doing more than those who wrote them had in mind (Derrida 1981). Inviting an unpredictable future, which he terms l'avenir - that which is to come (Derrida 2005). The reason for taking up art, and for talking about aesthetic practices, is just this. Art is when artifacts are made that are, we might say, paradoxically specialized in this becoming, in l'avenir.

You could say that innovation is at the heart of science and theory, too. It is, but in a different way. In theory, although we know that the meaning of our texts keeps changing through history, we always try to keep track of it, we always discuss what it means. In art, the point is just the

\footnotetext{
${ }^{9}$ In recent science and technology studies, this is an important point; Bruno Latour coined it nicely in the title of his article "The end of the means" (2002).
} 
opposite, to open up to ever new interpretations (Rancière 2013). And tradition is mainly used as inspiration and material, never as a way to establish and sanction meaning. You can always ask $m e$ to unfold and explain; conceptual accountability is at the core of my job, even if I hope to create new understandings; but don't ask the poet what the poem means - just read the poem!

This is important here because it implies that art opens to a great flexibility: If we use our senses and imagination, we can find ways to create prototypical narratives that work with people who are very diverse, and whose ways of engaging with cultural tradition we perhaps don't recognize at first. This doesn't mean there are no standards, as some critics of modern or post-modern art would perhaps claim. The standards that are taken up, performed, and recreated, as Halberg and Louie at Helsingung produce the song, or Kofod, Larsen and Sebastian at U-turn make a video, are aesthetic standards. They want to create something that is somehow beautiful and appealing, but first of all intriguing, captivating, worth spending time pondering over. Something that is recognizable, alludes to some kind of known tradition, while at the same time doing that in a way that takes off from that tradition, perhaps visibly quotes it, paraphrases it, mocks it, etc., or perhaps just puts it into a new context.

This implies a recalcitrance that takes it beyond the simple mirroring of preferred self-images. A nice example of this was provided by the production of the video with Sebastian that I referred to above. They recorded several 'takes', some of which featured a Sebastian who sang much more confidently and more in tune; but Kofod and Larsen, the artists-counsellors, persuaded him that this first take was far better, precisely with the tangible fragility of his trembling voice. The success of this educational process was in Sebastian's submission to this augmented aesthetic value - and in our appreciation of it - as much as in how it achieved an expression and recognition of his idiosyncratic experience, and of his courage in exposing it.

But this could not have been predicted. Aesthetic value is the paradoxical value of l'avenir, of the setting of new standards to come. Aesthetics, then, is what finally takes these performance standards beyond the idea of just going through movements, reproducing acts - without resting on the dubious assumption of therapeutic effect regardless of client subjectivity.

In sum, they can be user-driven in a way that is quite different from FIT because they are prototypical narratives, made in a collaborative practice that enacts and displays how life could be, objectified for a diverse and heterogeneous audience, with recalcitrant aesthetic artifacts, and with a view to the value of transforming values.

\section{$\underline{\text { 5. The social problem }}$}

This could all be simply the story of why we should just forget about addiction and social problems and focus instead on creative activities. But if all these things were made while just bracketing our knowledge that it's really methods applied at a drug treatment facility, and after all basically about addiction and therapy, it would not amount to much more than just refusing accountability. And all the points I've made here would be just about a surface performance, with something quite different going on behind the stage. In fact, in education and social work there is a long history of just that kind of pretense.

Rather, my fifth and final claim is that this should all be articulated as ways to address the pain, the suffering, the drama, the trauma, the doubts and fears, and the hopes and dreams, that we somehow share with those people whom we now call clients. In other words, it's a way to 
perform and construct addiction as a social problem, a problem for the community, and even perhaps for our culture as a whole, rather than as a problem for designated individuals.

If we zoom out a bit it becomes obvious that this is how it is with addiction. In our modern individualized cultures and communities, it is so easy to get lost in habits, to lose control; in particular, perhaps, to lose control of our self-control. This is a problem for all of us. One reason to take inspiration from Michael White is just that he realized this and thus took the whole narrative practice beyond an instrumental version of therapy that would ironically reproduce the instrumentalism of addiction itself (White 1997, Alexander 2008). The paradox of the therapeutic 'fix' is, in fact, one possible dead end of a purely pragmatic client-centered approach (Nissen \& Barington, 2016).

It is also easy to forget that our bad habits typically reflect social, ethnic, gendered or other kinds of inequalities. It is no coincidence that clients - or at least the target group population whom we ought to invite as clients - overwhelmingly represent the disadvantaged - those who have experienced trouble in school, those from poor families and so on. That is basically why we should overcome the idea that it is all about addiction as a diagnosed individual condition. And why the standards of our performances - in counselling or research - should be about that overcoming. That is the only way we can create prototypical narratives in this field that challenge our diagnostic culture without simply tabooing addiction and its social conditions and consequences.

This can be expressed in terms of equality of health, and in terms of how public services can help cultivate our communities on a large scale. But it can also be expressed in aesthetic ways, with stories and pictures and songs of real people whom we can recognize and who can recognize themselves as part of our communities.

\section{Conclusion}

These claims about the practices of aesthetic documentation represent aspects of my standpoint and contribution to an ongoing dialogue with counsellors, managers and users in and around the facilities $U$-turn and Helsingung, and in the wider fields of youth work, social work, and drug treatment. In terms of content, they articulate how, while what they do may be referred to and governed as 'counselling drug users', their performances also take it beyond that standard. They break up and expand the hardware of therapy - with its individualizing and stigmatizing implications - that otherwise would frame any 'language game' regardless of how radical a deconstruction and customization to individual users.

In terms of their form, they circumscribe an emergent infrastructure of practices, communities, and competences, which could be thought of as another bid for the currently evolving transdisciplinary forms of knowledge demanded in a post-industrial world - one that does not itself contribute to the instrumentalist culture with which we are losing control of our self-control, and one that allows a place for philosophy, arts and humanities as forms of self-reflection, at a time when religion seems otherwise to regain its grip on our imagination in all the holes and cracks and blind spots that the sciences keep producing.

\section{References}

Alexander, B. K. (2008). The Globalisation of Addiction. A Study in the Poverty of the Spirit. New York, Oxford University Press. 
Bank, M. and M. Nissen (2016). "Beyond Spaces of Counselling." Qualitative Social Work.

Baudrillard, J. (1994). Simulacra and simulation, University of Michigan press.

Boal, A. (2000). Theater of the Oppressed. New York, Pluto Press.

Bourriaud, N. (2005). Relationel æstetik. København, Det Kongelige Danske Kunstakademi.

Bowker, G. and S. L. Star (1999). Sorting Things Out. Classification and its Consequences. Cambridge, Mass./London, MIT Press.

Brecht, B. (1982). Über experimentelles Theater. Frankfurt am Main, Suhrkamp Verlag.

Busch, L. (2011). Standards - Recipes for Reality. Cambridge, Mass, MIT Press.

Butler, J. (1993). Bodies That Matter. On the Discursive Limits of Sex. New York, Routledge.

Butler, J. (1997). The Psychic Life of Power. Theories in Subjection. . Stanford, Cal., Stanford University Press.

De Shazer, S. (1991). Putting difference to work. New York, W.W.Norton \& Co.

Derrida, J. (1981). Plato's Pharmacy. Dissemination B. Johnson. Chicago, University of Chicago Press: 61-171.

Derrida, J. (2005). The Politics of Friendship. London, Verso.

Goffman, E. (1986). Frame Analysis. An Essay on the Organization of Experience. Boston, North Eastern University Press.

Halberg, M. (2013). "Skriften på væggen - gruppesamtaler som værdsættende ceremoni." Stof(22): 13.

Hanson, F. A. (1993). Testing Testing: Social Consequences of the Examined Life Berkeley University of California Press

Hart, J. T. (2006). "The political economy of health care: a clinical perspective."

Hegel, G. W. F. (1969). Hegel's Science of Logic. London - New York, Prometheus Books.

Hegel, G. W. F. (1977). Phenomenology of Spirit. Oxford, Clarendon Press.

Høgsbro, K. K. N., M. (2014). Narrative, Substance, and Fiction Addiction and Performance. J. R. Z.

Zontou. Newcastle upon Tyne, Cambridge Scholars Publishing: 151-177.

Jameson, F. (1998). Brecht and method, Verso.

Jensen, U. J. (1987). Practice and Progress: A Theory for the Modern Health Care System Oxford, Blackwell. 
Jensen, U. J. (1999). Categories in Activity Theory: Marx' Philosophy Just-in-time. Activity Theory and Social Practice: Cultural-Historical Approaches S. Chaiklin, M. Hedegaard and U. J. Jensen. Aarhus, Aarhus: University Press: 79-99.

Latour, B. (2002). "Morality and Technology. The End of the Means." Theory, Culture \& Society 19(5/6): 247-260.

Lave, J. (2011). Apprenticeship in Critical Ethnographic Practice Chicago, University of Chicago Press.

Lave, J. and E. Wenger (1991). Situated Learning. Legitimate Peripheral Participation. New York, Cambridge University Press.

Liberali, F. (2000). "Developing argumentative processes for critical reflection." Research Sig And Teacher Development SIG Special Joint Issue: 62-66.

Martin, E. (2007). Bipolar expeditions: Mania and depression in American culture, Princeton University Press.

Mattingly, C. (2010). The Paradox of Hope: Journeys Through a Clinical Borderland Berkeley / London, University of California Press.

Miller, S. D., et al. (2003). "The outcome rating scale: A preliminary study of the reliability, validity, and feasibility of a brief visual analog measure." Journal of brief Therapy 2(2): 91-100.

Miller, W. R. and S. Rollnick (1991). Motivational interviewing: Preparing people to change addictive behavior. New York, Guilford Press.

Mol, A. (2008). The Logic of Care. Health and the Problem of Patient Choice. New York, Routledge.

Newman, F. and L. Holzman (1996). Unscientific Psychology: A Cultural-Performatory Approach to Understanding Human Life Westport, CT, Praeger.

Nielsen, S. and K. Kofod (2013). "Æstetisk dokumentation af unges selv-fortællinger." Stof(21): 33-37.

Nissen, M. (2009). "Objectification and Prototype." Qualitative Research in Psychology 6(1): 67-87.

Nissen, M. (2012). The Subjectivity of Participation. Articulating Social Work Practice with Youth in Copenhagen London, Palgrave MacMillan.

Nissen, M. (2012). "Writing Drug Cultures." Culture \& Psychology 18: 198-218.

Nissen, M. (2013). "Beyond Innocence and Cynicism: Concrete Utopia in Social Work with Drug Users." Outlines.Critical Practice Studies.

Nissen, M. (2014). Could Life Be... Producing Subjectivity in Participation. Collaborative Projects. A. Blunden. London, Brill: 69-84.

Nissen, M. (2015). "Meeting youth in movement and on neutral ground." Dialogic Pedagogy: An International Online Journal 3. 
Nissen, M. (2016). "Standards and Standpoints. Why Standards, and Studying them, Imply Critique." Theory \& Psychology. 26:2, 163-181

Nissen, M. and K. Barington (2016). Numbers: Manageable Nothingness or User- Driven Standards? . Nothingness. J. W.-L. Bang, D.A., Information Age Publishing.

Norcross, J. C. (2011). Psychotherapy relationships that work: Evidence-based responsiveness, Oxford University Press.

Porter, T. (1995). "Trust in numbers." The pursuit of objectivity in science and public life: 50-51.

Rancière, J. (2013). Aisthesis: Scenes from the aesthetic regime of art, Verso.

Rowland, N., \& Goss, S. (Eds.). (2013). Evidence Based Counselling and Psychological Therapies: Research and Applications. London: Routledge.

Sackett, D. L., et al. (2000). Evidence-Based Medicine - How to Practice and Teach EBM Toronto, Churchill Livingstone.

Sloan, C. (2014). From Substance Misuse: The Musical To Double Whammy: The Affect Of Outside Edge Theatre Company. Addiction and Performance. J. Z. Reynolds, Z. London: 214-233.

Stengers, I. (1997). Power and invention. Situating science. Minneapolis, USA, University of Minnesota Press.

Stenner, P. (2016). "Valuation and standardization. Or, Proust's memory, Kierkegaard's self and Whitehead's evaluation: between limited activity and liminal value." Theory \& Psychology.

Suchman, L., et al. (2002). "Working artefacts: ethnomethods of the prototype." British Journal of Sociology 53(2): 163-179.

Thorgaard, K. (2010). Evidence, patient perspective and deliberative clinical decision-making, Aarhus University. PhD.

Timmermans, S. and S. Epstein (2010). "A world of standards but not a standard world: toward a sociology of standards and standardization*." Annual review of Sociology 36: 69-89.

Turner, V. (1995). The ritual process: Structure and anti-structure, Transaction Publishers.

White, M. (1997). Challenging the Culture of Consumption. Rites of passage and communities of acknowledgement. New Perspectives on Addiction M. Raven. Adelaide, AU, Dulwich Centre.

White, M. (2007). Maps of Narrative Practice. New York, W.W.Norton.

Wittgenstein, L. (2010). Philosophical investigations, John Wiley \& Sons. 